\title{
Practices and Attitudes of Nursing Students Toward Patients With Disordered Eating Behaviors
}

\author{
Kathryn Phillips \\ Fairfield University, kphillips1@fairfield.edu \\ Jenna A. LoGiudice \\ Fairfield University, jlogiudice@fairfield.edu
}

Follow this and additional works at: https://digitalcommons.fairfield.edu/nursing-facultypubs

Copyright (c) 2019 National League for Nursing, published by Lippincott Williams \& Wilkins. The author post-print has been archived here with permission from the copyright holder.

\section{Peer Reviewed}

\section{Repository Citation}

Phillips, Kathryn and LoGiudice, Jenna A., "Practices and Attitudes of Nursing Students Toward Patients With Disordered Eating Behaviors" (2019). Nursing and Health Studies Faculty Publications. 206. https://digitalcommons.fairfield.edu/nursing-facultypubs/206

\section{Published Citation}

Phillips, K. E., \& LoGiudice, J. A. (2019). Practices and Attitudes of Nursing Students Toward Patients With Disordered Eating Behaviors. Nursing education perspectives. doi: 10.1097/01.NEP.0000000000000449.

This item has been accepted for inclusion in DigitalCommons@Fairfield by an authorized administrator of DigitalCommons@Fairfield. It is brought to you by DigitalCommons@Fairfield with permission from the rightsholder(s) and is protected by copyright and/or related rights. You are free to use this item in any way that is permitted by the copyright and related rights legislation that applies to your use. For other uses, you need to obtain permission from the rights-holder(s) directly, unless additional rights are indicated by a Creative Commons license in the record and/or on the work itself. For more information, please contact digitalcommons@fairfield.edu. 


\begin{abstract}
Disordered eating (DE) behaviors are associated with obesity and eating disorders. This study describes the practices and attitudes (P\&A) of student nurses toward patients exhibiting DE and how students' own DE behaviors affects their P\&A. Despite most having had mental health rotation $(74.7 \%)$ and education on DE (68\%), only $34.7 \%$ feel prepared to screen for DE with only $44 \%$ taught to screen for DE. The group $(n=7)$ scoring high for DE behaviors themselves indicated greater rates of feeling prepared to screen. This knowledge can help nursing educators in designing curriculum to increase the preparation of nurses to address DE behaviors.
\end{abstract}




\section{Introduction/Background}

Disordered eating (DE) behaviors are associated with the development of clinically significant eating disorders and obesity (Neumark-Sztainer et al., 2006), making them of concern to nurses. If nurses are not addressing patients with DE behaviors due to their practices or attitudes $(P \& A)$, then these patients may miss an opportunity for help. Although student nurses receive education on mental health conditions, there is a gap in the literature addressing student nurses' P\&A toward patients with DE. Additionally, it is unknown how student nurses own DE behaviors may affect their P\&A toward patients with DE. Therefore, the purpose of this study was to describe student nurses' P\&A toward patients with DE behaviors, including how nursing students' personal DE behaviors may affect their P\&A.

To the author's knowledge, there is only one study of nursing students' attitudes toward working with patients with DE or eating disorders. In this study, $64.7 \%$ of nursing students reported feeling the patient with anorexia nervosa (AN) was responsible for their illness, and the average rating on how they like dealing with these patients was 2.84 (on a 5 point Likert), falling between disliking and neutral (Fleming \& Szmukler, 1992). When medical professionals and students liked caring for those with AN, it was correlated with knowledge of the disease (Fleming \& Szmukler, 1992).

\section{Methods}

\section{Measures}

Participants completed two survey instruments in addition to a demographic form. The first was the Eating Attitudes Test - 26 (EAT-26), a 26-item self-report inventory designed to screen for DE behaviors (Garner, Olmsted, Bohr, \& Garfinkel, 1982). The EAT-26 has three subscales: dieting, bulimia \& food preoccupation, and oral control. The mean score for a control sample of female subjects was 9.9 (9.2) while those with AN had 36.1 (17.0) (Garner et al., 1982). A score of 20 or above is indicative of needing further professional assessment. Mean reliability for the scale is .86 (Gleaves, Pearson, Ambwani, \& Morey, 2014). It has been validated in patients with AN (Garner \& Garfinkel, 1980). 
The EAT-26 also contains behavioral questions that ask about DE and weight control behaviors (Garner et al., 1982). The behavioral questions ask if they have done any of the following in the last 6 months: A, binge eating episodes with loss of control; B, purging; C, diet pills, laxatives, and diuretics; and D, excessive exercise. The answer choices allow for a response of: never, once a month, 2-3 times a month, once a week, 2-6 times a week, or once a day. Finally, there is a question (E) that asks whether or not they lost more than 20 pounds in the last 6 months and is answered as yes or no.

The second assessment instrument the participants completed was the Practices and Attitudes (P\&A) scale, a 7-item measure developed by the second author and reviewed by several nursing researchers. The P\&A scale asks the following in regard to DE: 1 , if they believe it's important to screen; 2 , if they were taught to screen; 3 , if they feel prepared to screen; 4 , if they consistently screen; 5 , if they currently screen as a student nurse; 6 , if they plan to screen as an $\mathrm{RN}$; and 7 , if they will become aware of patient resources in their area. The response to each was answered on a scale of 1 strongly disagree to 5 strongly agree with 3 being neither agree nor disagree.

\section{Procedures}

The researchers invited student nurses to participate in the study at a national conference for student nurses. Any student nurse over the age of 18 was invited to participate. The study was explained and any questions were answered prior to handing out the study forms. The Institutional Review Board (IRB) at XXX University approved the study and all participants provided written informed consent.

Body mass index (BMI) was calculated based on self reported height and weight. The EAT-26 behavioral questions were scored as positive if they indicated they had ever (once a month, 2-3 times a month, once a week, 2-6 times a week, once a day or more) performed the behavior (e.g. binge eating, vomiting, etc.). The last behavioral question $(E)$ asks about losing more than 20 pounds in the past 6 months. If they said yes to this question, it was scored as a positive answer. 
The Statistical Package for the Social Sciences (SPSS) $22 \circledast$ was used to create the database and analyze the results. For demographic data, means and standard deviations were calculated for ratio level data. Chi-square analysis was used for categorical demographic data.

There were 81 students who consented to be in the study and filled out study instruments. Of these 75 completed both the EAT-26 and the P\&A.

\section{Results}

Subjects ( $n=75)$ were $94.7 \%$ female, $76 \%$ Caucasian with an average age of 23.2 (SD 4.3) years and a BMl of 25 (SD 4.9) kg/m². They were enrolled in Bachelor's degree (77.3\%) programs at public schools (58.7\%) in 16 states. A third were overweight or obese (34.3\%). Most (68\%) indicated they had received education on DE in their nursing program. Almost half (45.3\%) had worked as a nursing aid and the majority (74.7\%) had had at least 1 mental health rotation. Most reported never smoking (86.7\%), drank a maximum of 2 cups of coffee a day ( $88 \%)$, and had no more than 2 alcoholic drinks per week ( $80 \%)$.

There were 7 students with EAT-26 scores at or above the cutoff of 20 . For these students, the average age was 23.6 (SD 2.2) and their BMI was 26.4 (SD 6.3) $\mathrm{kg} / \mathrm{m}^{2}$. Most were Caucasian (57.1\%) with $28.5 \%$ Asian and $14.3 \%$ Hispanic. They were primarily seniors $(71.4 \%)$ from public schools $(71.4 \%)$ of nursing in California (28.6\%) with most reporting they received DE education (85.7\%) in their program.

Mean scores for the EAT-26 and percentages that engaged in each of the DE behavioral items for the entire sample were as follows: global score 8.2 (SD 8.8), dieting 5.5 (SD 6), bulimia and food preoccupation 1.0 (SD 2.4), oral control 1.7 (SD 2.3), A 17.3\%, B 4\%, C 6.7\%, D 40\%, and E 4\%. For the high scoring subset of students (n=7), EAT-26 scores and percentages were: global score 29.6 (SD 1.1), dieting 18.7 (SD 7.9), bulimia and food preoccupation 5.7 (SD 5), oral control 5.1 (SD 4.8), A 42.9\%, B $28.6 \%$, C $28.6 \%$, D $57.1 \%$, and E $14.3 \%$. The percentage that agreed with each of the P\&A questions for the entire sample was: $1,84 \% ; 2,44 \% ; 3,34.7 \% ; 4,25.3 \% ; 5,25.3 \% ; 6,72 \% ; 7,86.7 \%$. For the subset of students ( $\mathrm{n}=7$ ) it was: $1,100 \% ; 2,71.4 \% ; 3,57.1 \% ; 4,57.1 \% ; 5,42.9 \% ; 6,100 \% ; 7,100 \%$. 


\section{Discussion}

This study describes the P\&A of a sample of student nurses with description of how their own DE behaviors may affect their P\&A. Despite the majority of the sample having had a mental health rotation (74.7\%) and education on DE (68\%), only $34.7 \%$ report feeling prepared to screen for DE with only $44 \%$ having been taught to screen for DE. These findings on the preparation of nurses to address a common health concern indicate the need to discuss DE behaviors, screening, and treatment in nursing education.

Compared to prior work on nursing students, the mean EAT-26 score in the present study is similar. Results from single college studies of nursing students indicate the mean EAT-26 score in the present sample (8.2) is slightly lower than one (10.6) group of nursing students (Phillips et al., 2015) and higher than that reported on a group of accepted nursing students (4.9) (Szweda \& Thorne, 2002). In the present study, $9.3 \%(n=7)$ of the sample scored above the cutoff $(>20)$ for the EAT-26. These 7 students indicated higher rates of agreement with every question on the P\&A scale. Personal DE behaviors may inform a student nurse, raising their subjective sense of preparation to address DE behaviors in their patients. Of note, a higher percentage of these students $(n=7)$ indicated they received DE education and agreed with having been taught to screen for DE compared to the overall sample $(n=75)$, which raises the question of whether or not student nurses are being educated on DE. Perhaps individuals with DE behaviors remember DE education more vividly than those without DE behaviors because it has a personal context in their life. Another way this could be understood is in relation to the theory of health as expanding consciousness (Newman, 1999). In this context, the higher scoring individuals experienced DE, which caused them to develop a higher level of consciousness, leading to greater understanding of DE.

Another finding of note, consistent with national trends of college students (Lipson \& Sonneville, 2017), was that over a third (34.3\%) of the sample was overweight or obese. This may, in part, be due to the fact that $17.3 \%$ reported binge eating, which is linked to overweight and obesity in college students (Kelly-Weeder, Phillips, Leonard, Veroneau, 2013). College students report BE frequently occurs in 
response to stress (Phillips, Kelly-Weeder, \& Farrell, 2016) and nursing students may experience significant stress due to the rigors of nursing school (Alzayyat \& Al-Gamal, 2014). Due to the stress of nursing school, students may utilize unhealthy coping mechanisms such as binge eating, thereby increasing their risk for obesity. This is significant for nurse educators because BMI has a negative relationship with academic performance in college (Anderson \& Good, 2016). Nursing students may benefit from education on stress reduction and self-care practices to improve their health and lower stress.

Although this is a small sample $(n=75)$, the students came from 16 states, giving strength to the findings. All answers were given anonymously, increasing the chances of honest responses. In the future, it would be helpful to add qualitative data to better understand the effects of personal DE behaviors on the P\&A of student nurses toward patients with DE.

Disordered eating behaviors are a common concern that can lead to clinically significant eating disorders as well as obesity and related health concerns. It's imperative for nursing students to be educated on DE behaviors and feel prepared to screen patients for these concerns. Nursing faculty can help by educating student nurses about DE behaviors, screening questions, and treatment resources. Given the fact that over a third of the sample was overweight or obese, it would be helpful to teach self-care techniques that may assist nurses in maintaining a normal weight and prevent health complications.

\section{References}

Alzayyat, A., Al-Gamal, E. (2014). A review of the literature regarding stress among nursing students during their clinical education. International Nursing Review, 61, 406-415.

Anderson, A. S., \& Good, D. J. (2017). Increased body weight affects academic performance in university students. Preventative Medicine Reports, 5, 220-223. doi: 10.1016/j.pmedr.2016.12.020

Fleming, J. \& Szmukler, G. I. (1992). Attitudes of medical professionals towards patients with eating disorders. Australian and New Zealand Journal of Psychiatry, 26, 436-443. 
Garner, D. M., \& Garfinkel, P. E. (1980). Socio-cultural factors in the development of anorexia nervosa. Psychological Medicine, 10(4), 647-56.

Garner, D. M., Olmsted, M. P., Bohr, Y., \& Garfinkel, P. E. (1982). Eating attitudes test: Psychometric features and clinical correlates. Psychological Medicine, 12, 871-878.

Gleaves, D. H., Pearson, C. A., Ambwani, S., \& Morey, L. C. (2014). Measuring eating disorder attitudes and behaviors: A reliability generalization study. Journal of Eating Disorders, 2(6). Retrieved from http://www.jeatdisord.com/content/2/1/6

Kelly-Weeder, S., Phillips, K., Leonard, K., \& Veroneau, M. (2013). Binge eating and weight loss behaviors of overweight and obese college students. Journal of the American Association of Nurse Practitioners, 26(8), 445-451.

Lipson, S. K., \& Sonneville, K. R. (2017). Eating disorder symptoms among undergraduate and graduate students at 12 U.S. colleges and universities. Eating Behaviors, 24, 81-88. doi: 10.1016/j.eatbeh.2016.12.003

Neumark-Sztainer, D., Wall, M., Guo, J., Story, M., Haines, J., \& Eisenberg, M. (2006). Obesity, disordered eating, and eating disorders in a longitudinal study of adolescents: How do dieters fare 5 years later? Journal of the American Dietetic Assocation, 106(4), 559-68. doi: 10.1016/j.jada.2006.01.003

Newman, M. A. (1999). Health as expanding consciousness ( $2^{\text {nd }}$ ed.). New York, NY: National League for Nursing Press.

Phillips, K., Kelly-Weeder, S., \& Farrell, K. (2016). Binge eating behavior in college students: What is a binge? Applied Nursing Research, 30, 77-11. doi: 10.1016/j.apnr.2015.10.011

Phillips, L, Kemppainen, J. K., Mechling, B. M., MacKain, S., Kim-Godwin, Y., \& Leopard, L. (2015). Eating disorders and spirituality in college students. Journal of Psychosocial Nursing, 53(1), 30-37.

Szweda, S., \& Thorne, P. (2002). The prevalence of eating disorders in female health care students. Occupational Medicine, 52(3), 113-119. 